\title{
Preclinical evaluation of antioxidant, anti- inflammatory, cytotoxic and lipid-lowering properties of a nutraceutical from Curcuma longa cultivated in Cuba
}

\begin{abstract}
Summary
In Cuba, Curcuma longa, is originally found in the mountainous regions of Pinar del Rio and Santiago de Cuba. Since ancient times this plant has been used primarily in Asia as a food, cosmetic and herbal medicine, nevertheless in our country there is not report of the traditional use. Due to population aging and the increase of chronic non communicable diseases, the development of nutraceuticals has become of interest in our country. In the present work we evaluated a nutraceutical prepared with Curcuma longa cultivated in the Artemisa region. We determined the antioxidant activity by DPPH and FRAP methods, the anti-inflammatory activity in vivo in the cotton disc-induced granuloma model, the cytotoxic effect in the human tumor line NCI-H460 and the lipid-lowering properties in knockout ApoE mice. The results showed that the nutraceutical is capable of sequestering DPPH depending on the concentration used, with a mean inhibitory concentration of $150 \mathrm{ug} / \mathrm{ml}$ and high ferroreductive activity even at the concentration of $0.25 \mathrm{mg} / \mathrm{ml}$. In the granuloma model in mice the nutraceutical reduced systemic inflammation and cell infiltration and inhibited the formation of granuloma in a dose-dependent effect with an average effective dose of $3,245 \mathrm{mg} / \mathrm{kg}$, which is interesting in a natural product. It also showed cytotoxic potential in the human tumor cells NCI-H460 with a high anti-proliferative activity in this line. The trials with APOE knockout mice indicated that the nutraceutical not only promotes lipid lowering and atheroma decreasing, but also improves vessel wall condition in atherosclerotic pathology.
\end{abstract}

Keywords: nutraceutical, Curcuma longa, turmeric, antioxidant, anti-inflammatory, lipid lowering, cytotoxicity, preclinical studies
Volume 7 Issue 6 - 2019

Valdés-González T,' Infante-Burzac JF,' Arteche-García J, ${ }^{1,2}$ Oliva-Hernández R, ${ }^{3}$ Fariñas-Medina $M,^{3}$ Fernández-Salazar $T^{3}{ }^{3}$ Rodeiro-Guerra 1,4 Hernández-Balmaseda 1,4 Riera-Romo $\mathrm{M}^{4}{ }^{4}$ Ido $\mathrm{T}^{5}$

'Theragnostic Laboratory, University Hospital General Calixto García, Cuba

${ }^{2}$ Center for Technological Applications and Nuclear

Development (CEADEN), Cuba

${ }^{3}$ Finlay Vaccine Institute (IFV), Cuba

${ }^{4}$ Institute of Marine Sciences Institute (ICIMAR), Cuba

${ }^{5}$ Neuroscience Research Institute, GachonUniversity, South Korea

Correspondence: Dr. Tania Valdés-González, PhD Theragnostic Laboratory, University Hospital General Calixto García University Ave. and G. Plaza de la Revolución, 10400 Havana, Cuba,Tel 53-78382I7I, Email taniavalde@infomed.sld.cu

Received: November 14, 2019 | Published: December 16, 2019

\section{Introduction}

In Cuba, Curcuma longa (C. longa) is originally found in the mountainous regions of Pinar del Rio and Santiago de Cuba but there are not reports about the traditional use of this plant. Recently, as the benefits of $C$. long $a^{1-5}$ are known in our country, its cultivars have been extended and currently we can find it in different regions of the country, including the central region where there are large cultivar areas.

C. longa, common name turmeric, is a herbaceous plant native from southwest India and belonging to Zingiberacea family. The most important chemical components of turmeric are a group of compounds called curcuminoids, which include curcumin (diferuloylmethane), demethoxycurcumin and bisdemethoxycurcumin. The best studied compound is curcumin, which constitutes $3.14 \%$ (on average) of turmeric powder. ${ }^{6}$ In addition there are other important volatile oils such as turmeron, atlantone and zingiberene. Some general constituents are sugars, proteins and resins.

In order to find the potential therapeutic or preventive effects numerous studies have been focused on the phytochemicals contained in of $C$. longa. Diseases such as arthritis, diabetes ${ }^{7}$ and cancer ${ }^{8-10}$ have been the focus of this research. Curcumin has been shown to inhibit protein kinase $\mathrm{C}$ and the expression of several oncogenes in murine skin cancer models. ${ }^{8}$ Other results show the anti-carcinogenic and chemo-preventive activity of turmeric in colorectal cancer and other types of malignant and inflammatorylesions. ${ }^{9,10}$ Some researchers even suggest the existence of epigenetic mechanisms involved in the chemo-preventive and anti-inflammatory effects of $C$. longa metabolites. ${ }^{11}$

Currently the development of nutraceuticals with high therapeutic or preventive properties is an important topic in Cuba. A nutraceutical, according to definition, is a dietary supplement, presented in a nonfood matrix (pills, capsules, powder, etc.), of a concentrated natural bioactive substance usually present in food and which, taken in a dose higher than that existing in that food presumably has a favorable effect on health, greater than what normal food could have. Since 2016, the development of a nutraceutical from C. longa is a research project associated to the National Program of Natural and Traditional Medicine of the Cuban Ministry of Public Health.

Due to the population aging the impact on chronic non communicable diseases and on the oxidative stress directly associated to these pathologies, are a focus for the use of nutraceuticals. Oxidative stress is caused by a short-term or long-term imbalance between antioxidants and pro-oxidants, in favor of oxidants, which 
causes disruption of signaling and cellular control mechanisms. ${ }^{12}$ Although high levels of reactive oxygen species (ROS) can damage a wide variety of molecules, the production of ROS is essential for the physiology of normal cells. ${ }^{13}$ The balance between ROS and the antioxidant capacity of cells is very important for normal metabolism, signal transduction and regulation of cellular functions. ${ }^{14}$

In the case of cancer, the relationship with oxidative stress has been the subject of intense debate due, mainly, to the welldocumented fact that tumor cells have high levels of ROS compared to normal cells. ${ }^{15}$ However, numerous antioxidant compounds and molecules have demonstrated cytotoxic and antitumor capacity, indicating that there is more than one mechanism involved in this type of pharmacologicalactivities. ${ }^{16,17}$ Natural extracts obtained from both marine and terrestrial plants are rich in poly-phenolic compounds with high antioxidant and anti-inflammatoryactivity. ${ }^{17}$ Oxidative stress has been correlated with the ability to induce mutations in tumor cells, since ROS can form adducts, modify the primary structure and cause DNA damage, increasing themutationrate. ${ }^{18}$ These modifications and oxidative damage to DNA are closely related to the inflammatory process and carcinogenesis. ${ }^{19}$

In the present work we evaluated the antioxidant, antiinflammatory, cytotoxic and lipid-lowering properties using in vitro and in vivo models, of a nutraceutical of $C$. longa cultivated in Cuba in the Artemisa region.

\section{Methods}

\section{Nutraceutical}

The nutraceutical was prepared from $C$. longa harvested in the Province of Artemisa, with Good Production Practices. It was approved for the use according to Cuban Standard Regulations.

\section{Cell line}

The tumor line 1NCI-H460 (non-small cell human lung adenocarcinoma) was acquired from ATCC and cultured in RPMI medium $10 \%$ fetal bovine serum and $1 \%$ penicillin / streptomycin, according to the manufacturer's recommendations. The cells were maintained in exponential phase of growth at $37^{\circ} \mathrm{C}$ and $5 \% \mathrm{CO}_{2}$.

\section{Animals}

The experiments were approved by the Ethic Committee of the institutions participant in the study. Balb/c mice and ApoE knockout mice were used in this study. The animals were obtained from the National Center for the Production of Laboratory Animals (CENPALAB), they were received with their corresponding certificates of hygienic-sanitary and genetic quality. The animals were kept in the Finlay Institute bioterium in groups of three animales, with free access to food and water. The temperature, humidity and light were controlled $\left(22 \pm 1^{\circ} \mathrm{C} ; 55 \pm 5 \%\right.$; and light/dark cycle $12 \mathrm{~h} / 12$ $\mathrm{h}$, respectively). To select the experimental groups, it was taken into account that the animals were clinically healthy and that the weights were homogeneous, assigning the treatments randomly.

\section{Determination of antioxidant activity}

\section{$\alpha$ - $\alpha$-Diphenyl- $\beta$-picrilhydrazyl (DPPH) method}

The antioxidant activity was evaluated by determining the sequestration activity of the DPPH radical by the Brand-Williams method, with some modifications. ${ }^{20}$

\section{Plasma Ferroreductive Activity (FRAP)}

This method evaluated the antioxidant capacity of the nutraceutical according to its ability to reduce ferric iron $(\mathrm{Fe} 3+)$ present in a complex with 2,4,6-tri (2-pyridyl)-s-triazine (TPTZ) tothe ferrous form $(\mathrm{Fe} 2+)$, which has a maximum absorbance at a wavelength between $590-595 \mathrm{~nm}^{21}$

\section{Determination of anti-inflammatory activity}

It was performed by the method of granuloma induced by cotton discs. Groups of 10 male Balb/c mice each were used. The anesthetized animals received two $2 \mathrm{~cm}$ incisions in the inter-scapular region of each animal (on each flank of the animal), and a sterile and cotton disc was introduced in each incision. The average weight of the cottons was $10 \pm 2 \mathrm{mg}$. The wound was then sutured and post-surgical sepsis prevention was performed by topical application of procaine penicillin.

From the next day after cotton implantation and for 8 consecutive days, the nutraceutical of $C$. longa was administrated at 6 different concentrations $(0.1,1,10,50,100$ and $200 \mathrm{mg} / \mathrm{kg})$ using intragastric cannula. The euthanasia of the animals was performed, the granulomas formed were removed from the tissue, and placed in Petri dishes to be weighed in analytical balance to determine their wet weight (this value indicates the action of the substance at the level of edema in the inflammation). Subsequently, they were dried in an oven for 24 hours and weighed again to determine their dry weight (related to the amount of connective tissue present). Control animals only received $0.5 \%$ carboxy methyl cellulose (CMC), which constituted the vehicle in which the products were solubilized. Dexomethasone was used as a positive control of the experiment and was administered in a reference group at $3 \mathrm{mg} / \mathrm{kg}$, intra-peritoneally approximately $3 \mathrm{~h}$ before sacrifice.

\section{Determination of cytotoxic activity}

\section{Cell viability test}

To determine the cytotoxic effect of the products under study on the human tumor line, the cells were treated with increasing concentrations of eachextract $(0.1-1000 \mathrm{ug} / \mathrm{mL})$ and the cell viability of the culture was determined after $48 \mathrm{~h}$ incubation. Concentrations were tested in triplicate and cell viability was determined by the violet crystal method. ${ }^{22}$

\section{Lipid lowering effect}

Groups of 5 female mice of the 42-week ApoE knockout line were used. The nutraceutical equivalent to $200 \mathrm{mg} / \mathrm{kg}$ was supplied daily orally daily with intragastric cannula for three months. Determinations of cholesterol and triglycerides were performed at the end of the test with the extraction of blood samples through the retro-orbital plexus.

Pathological investigations were carried out by conventional methods. The macroscopic alterations were collected in protocols established for this purpose, while for histo-pathological studies were performed by fixing the selected fragments of tissues in $10 \%$ neutral formalin. The samples obtained were processed by the inclusion technique and paraffin sections, and colored with Hematoxylin Eosin (H.E). In addition, atheroma and vessels were analyzed with a system (hardware and software) designed in our laboratory for pathological studies. 


\section{Statistical analysis}

In all the cases the graphs and values were generated using GraphPrism 5 software. For the anti-inflammatory activity with the granuloma animal model the statistical analysis was performed for $\mathrm{p}$ $<0.05, \mathrm{p}<0.01$ and $\mathrm{p}<0.001$ (Anova and the Dunnett test a posteriori). In the case of lipid lowering experiments, for the biochemical and histological parameters with knockout mice, the level of statistical significance was $\mathrm{p}<0.05$ in all the cases. All ANOVA results are detailed in the legends of the figures for easier reading.

\section{Results}

\section{Determination of antioxidant activity}

The ability to sequester free radicals is one of the primary criteria of antioxidant activity. In this sense, $C$. long $a$ extracts were evaluated for their ability to sequester the DPPH radical in vitro. Figure 1 shows the concentration-response curves of the inhibition percent of this radical by the nutraceutical. As it is shown in the graph, the nutraceutical is capable of sequestering DPPH depending on the concentration used, with an IC50 of $150 \mathrm{ug} / \mathrm{ml}$.

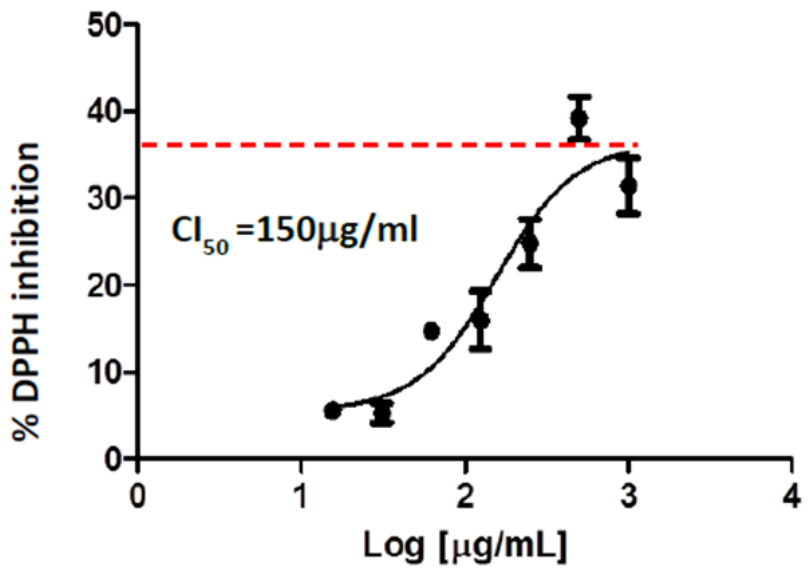

Figure I DPPH radical sequestration by the nutraceutical of C.longa The inhibition percent of the radical as a function of the logarithm of the concentration is shown and the calculated IC50 value is specified. The IC50 graphs and values were generated using GraphPrism 5 software.

The antioxidant capacity of these extracts was also evaluated according to their $\mathrm{Fe} 3$ + reducing activity through the FRAP test, since iron in ferric form is able to react with free radicals contributing to the formation of ROS. Table 1 shows the equivalent values of ascorbic acid determined by this method, that show a high ferroreductive activity even at the concentration of $0.25 \mathrm{mg} / \mathrm{ml}$. Different authors have determined in extracts of $C$. long $a$ that there is a positive linear correlation between the total phenolic content and the reducing activity. They have also shown that the anti-radical activity in the plant is a consequence of the concentration of some of its secondary metabolites specifically, the curcuminoids. ${ }^{23,24}$ It has also been proven that geographical variation, in addition to other factors such as soil type, climate, cultivation method, rainfall, drastically affect the content of curcumin in C. long $a^{23}$ and consequently its antioxidant activity.

\section{Determination of anti-inflammatory activity}

The nutraceutical was evaluated for its anti-inflammatory effects in a granuloma model induced by cotton discs in Balb/c mice. Figure 2 shows the granuloma weight values in $\mathrm{mg}$ for the doses evaluated, which were compared with control animals and with animals administered with Dexamethasone as an anti-inflammatory control. Similarly, the nutraceutical dose-response behavior was evaluated from the granuloma weight data obtained from the previous model. The nutraceutical is able to inhibit the formation of granuloma in a dose-dependent effect with an average effective dose of $3,245 \mathrm{mg} / \mathrm{kg}$ (Figure 3). These results together demonstrate that the nutraceutical has anti-inflammatory activity, being able to reduce in vivo local and systemic inflammation and cell migration induced by a foreign body. In this model of chronic inflammation, the nutraceutical from $C$. longa showed activity in a dose lower than $10 \mathrm{mg} / \mathrm{kg}$, which is very interesting considering that it is a natural product.

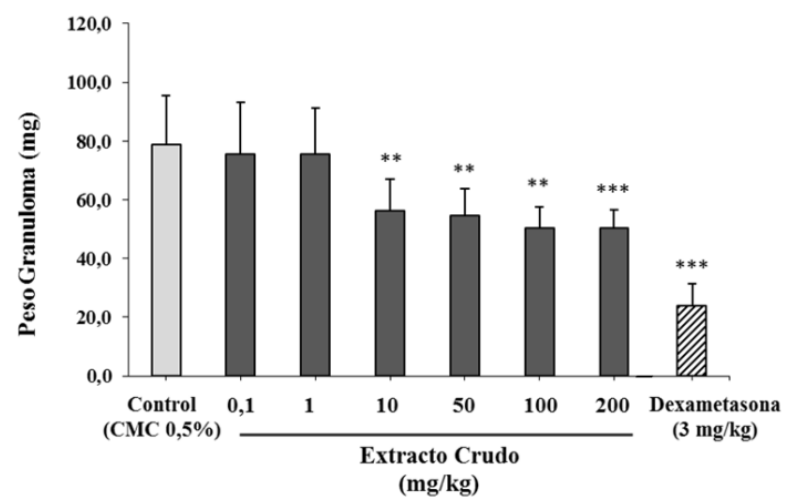

Figure 2 Effect of the nutraceutical of $C$. longa on granuloma formation. The average granuloma weight of the animals treated with each dose is shown. The control group was only administered with $0.5 \%$ carboxymethyl cellulose. Animals treated with $3 \mathrm{mg} / \mathrm{kg}$ i.p. Dexamethasone $3 \mathrm{~h}$ before sacrifice constitutes a positive control of the experiment. A significant decrease in granuloma weight is observed for the groups treated with doses of 10,50, 100 and $200 \mathrm{mg} / \mathrm{kg}$ (Anova and the Dunnett test a posteriori) ${ }^{*} \mathrm{p}<0.05,{ }^{*} \mathrm{p}<0,0$ I and $* * * p<0.001$.

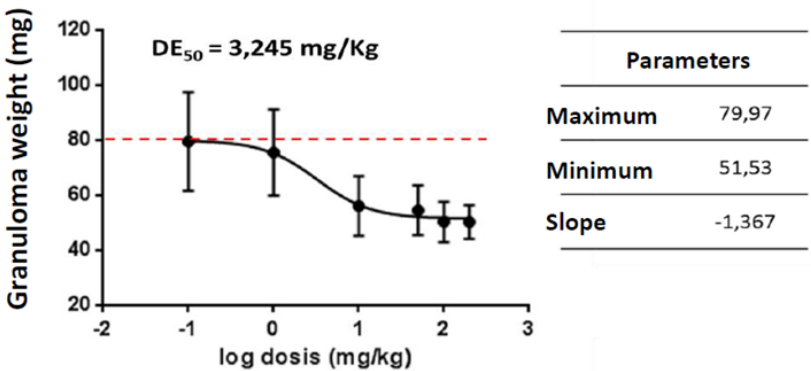

Figure 3 Dose-response curve of the anti-inflammatory activity of the nutraceutical of $C$. longa. The average weight of the granuloma of the treated animals is shown according to the logarithm of the dose in $\mathrm{mg} / \mathrm{kg}$. The nutraceutical inhibits granuloma formation in this model in a dose-dependent manner. Inhibition parameters were calculated using GraphPrism 5 software and an average effective dose (ED50) of $3,245 \mathrm{mg} / \mathrm{kg}$ body weight was determined. 
Oxidative stress is closely related to inflammation and it is known that free radicals are capable of causing damage to different biomolecules such as DNA, lipids and proteins. These oxidative damages promote cell death, the release of pro-inflammatory substances and increase the activity and recruitment of cells of the immune system, which determines the development of the inflammatory response. The close relationship between the processes of inflammation and oncogenesis has also been demonstrated. These processes modulate each other and have common molecular targets. Therefore, it is expected that a product with high anti-inflammatory activity also has antioxidant and cytotoxic/ antitumor properties.

\section{Determination of cytotoxic activity}

In another experimental block, cytotoxicity as a criterion of its potential antitumor activity, was evaluated in the NCI-H460 line (nonsmall cell human lung adenocarcinoma). Cell viability was determined by vital staining with violet crystal. The Figure 4 shows that the nutraceutical is able to decrease the cell viability of the treated cells with respect to untreated cells or cells incubated with $1 \%$ DMSO as a control (vehicle in which the extracts are solubilized). The low mean inhibitory concentration (IC50) demonstrates the anti-proliferative effect of the nutraceutical (Table 3). C. longa is rich in curcuminoids and other bioactive substances with high antioxidant activity, as showed in this work, capable of modulating molecular targets of the inflammatory cascade and related to malignant transformation.

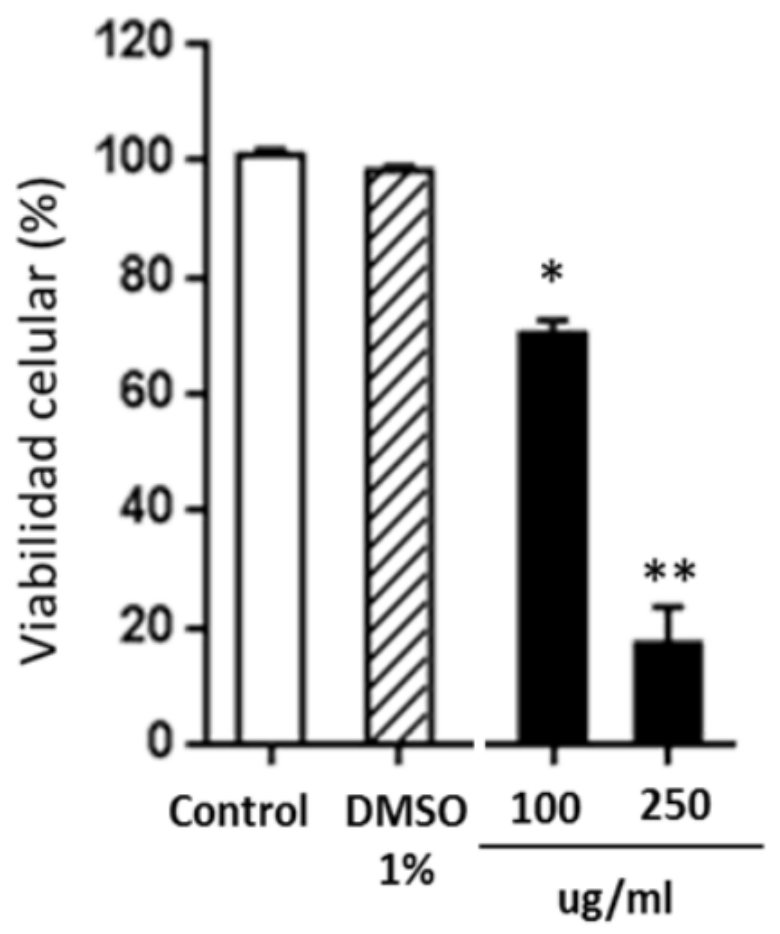

Figure 4 Cytotoxicity of the nutraceutical of $\mathrm{C}$. longa in $\mathrm{NCl}-\mathrm{H} 460$ cells. The percentage of cell viability of the $\mathrm{NCl}-\mathrm{H} 460$ line, untreated (control), treated with $1 \%$ DMSO or exposed to concentrations of 100 and $250 \mathrm{ug} / \mathrm{ml}$ is shown; ${ }^{*} p<0.05$ and $*^{*} p<0.01$ with respect to control cells (Anova and the Dunnett test a posteriori). The cells were incubated with the products for $48 \mathrm{~h}$, in triplicate. The graph was generated using GraphPrism 5 software.
Table I Ferroreductive activity of the nutraceutical of $C$. longa

\begin{tabular}{ll}
\hline Concentration $(\mathbf{m g} / \mathbf{m l})$ & $\boldsymbol{\mu M}$ equivalents of ascorbic acid \\
\hline $\mathrm{I}$ & 369,56 \\
0,5 & 302,89 \\
0,25 & 176,22
\end{tabular}

aThe ability to reduce $\mathrm{Fe} 3+$ as a function of the concentration tested is shown as $\mu \mathrm{M}$ equivalent of ascorbic acid

Table 2 Antiinflamatory activity

\begin{tabular}{lllll}
\hline Treatment & $\begin{array}{l}\text { Dosis }(\mathbf{m g} / \\
\mathbf{k g})\end{array}$ & $\begin{array}{l}\text { TW } \\
(\mathbf{m g})^{\mathbf{a}}\end{array}$ & $\begin{array}{l}\text { GAT } \\
(\mathbf{m g})^{\mathrm{b}}\end{array}$ & AA (\%) \\
\hline Control & CMC (0,5\%) & 88,85 & 18,38 & --- \\
\hline & 0,1 & 89,57 & 18,97 & 4,40 \\
& 1 & 85,51 & 16,63 & 4,23 \\
Nutraceutical & 10 & $66,10 * *$ & $17,\left.2\right|^{\mathrm{c} *}$ & 28,85 \\
& 50 & $64,57 * *$ & $14,\left.5\right|^{* *}$ & 30,79 \\
& 100 & $60,34 * *$ & $11,55 * * *$ & 36,15 \\
& 200 & $60,33 * * *$ & $12,40 * * *$ & 36,17 \\
\hline Dexamethasone & 3 & $26,12 * * *$ & $9,95 * * *$ & 69,56 \\
\hline
\end{tabular}

${ }^{a}$ TW: Transudative Weight. (Wet granuloma weight-Dry weight). It represents the formed edema

${ }^{\text {b} T A G: ~ G r a n u l o m a ~ A s s o c i a t e d ~ T i s s u e . ~(D r y ~ w e i g h t-C o t t o n ~ d i s c ~ w e i g h t) . ~}$ Represents cell infiltration

'AA: Anti-inflammatory Activity. (Granuloma weight control-Granuloma weight treated) $\mathrm{x} 100 /$ granuloma weight control

${ }^{*} \mathrm{p}<0.05, * * \mathrm{p}<0.01$ and $* * * \mathrm{p}<0.001$ (ANOVA and Dunnett a posteriori)

Table 3 IC50 values for nutraceutical in cells $\mathrm{NCl}-\mathrm{H} 460$

\begin{tabular}{ll}
\hline Cellular line & $\mathrm{Cl}_{50}{ }^{\mathrm{a}}(\mu \mathrm{g} / \mathrm{mL})$ \\
\hline $\mathrm{NCl}-\mathrm{H} 460$ & 140
\end{tabular}

${ }^{a}$ Concentration that decreases cell viability by $50 \%$

\section{Lipid lowering effect}

In the present study we demonstrate the effects of the nutraceutical on the atherosclerotic pathological processes in knock out APOE mice, as well as its possible safety in this animal species. During the daily observations, the animals did not present clinical alterations and there was no mortality in any of the experimental groups which indicate the safety of the nutraceutical in the doses and frequencies used in the test protocol.

The biochemistry analysis showed a significant decrease in cholesterol and triglyceride values for animals treated with the nutraceutical (Figure 5). The pathological lesions observed in ApoE 
mice showed all known phases of atherogenesis and the accompanying inflammatory response that has been observed in different species such as rabbits, non-human and human primates. It was observed that in the treated animals the measurements of the artery wall were lower than that of the untreated animals. On the other hand, the size of the atheroma located in the vascular wall was larger in the untreated animals than in the animals that received the nutraceutical. In the same way the wall / atheroma ratio is higher in the animals that did not receive the treatment (see Figures 6, 7 and 8 and Tables 4, 5). The initial alterations of the vascular walls consisted of accumulations of muco polysaccharide-rich substances at the level of the intima of the arteries, while the internal elastic membrane presented irregular contours, partial duplications and risk of cardiovascular events.

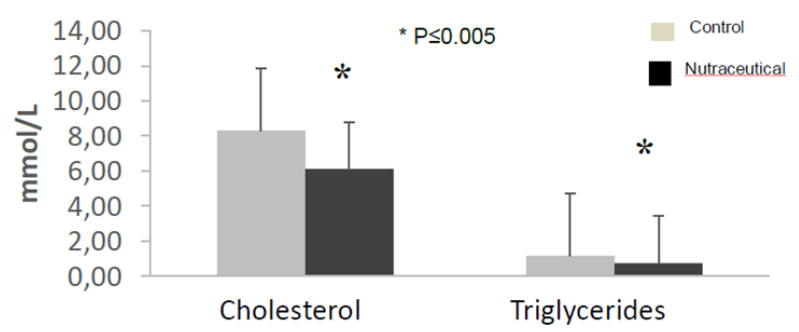

Figure 5 Cholesterol and triglyceride determinations in ApoE knockout mice treated with the nutraceuticals compared to controls ( $n=5$, ${ }_{p}<<0.05$, Anova test).

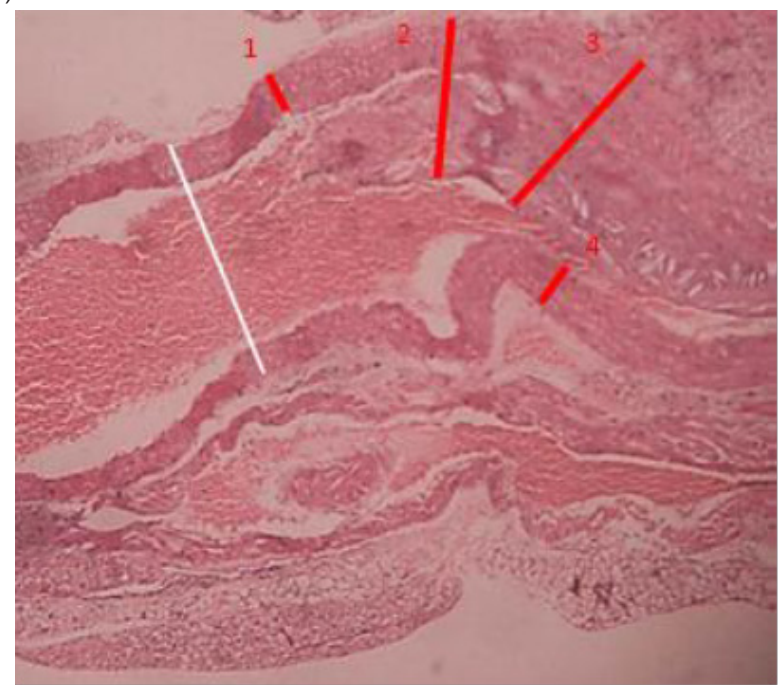

Figure 6 ApoE mouse without treatment, observe thickening of the vascular walls and presence of large atheromas in the lumen of the vessel. H.E.xI20.

Dyslipidaemia is characterized by increased blood levels of total or LDL cholesterol and triglycerides, or decreased HDL cholesterol levels, and is a risk factor for cardiovascular disease. The anti-atherogenic effects of the nutraceutical from $C$. longa that are due mainly to the curcumin concentration arise from multiple mechanisms, including direct curcumin's antioxidant potential for scavenging various ROS. The putative linkage of free-radicals-to-blood lipid peroxidation, such as ox-LDL, is the major cause in the pathogenesis of atherosclerosis and cardiovascular diseases. The cardio-protective properties of curcumin are primarily attributed directly to its inhibitory effects on inflammation and oxidative stress. ${ }^{25}$ Oxidative stress arises from the excessive formation of ROS, which are endogenously formed as byproducts of metabolic reactions. Curcumin has been shown to be effective in eliminating a variety of ROS including superoxide anion radicals, hydroxyl radicals, and nitrogen dioxide radicals. ${ }^{26}$ It is assumed that the unique conjugated structure of curcumin acts as a radical-trapping structure as well as a chain-breaking antioxidant.

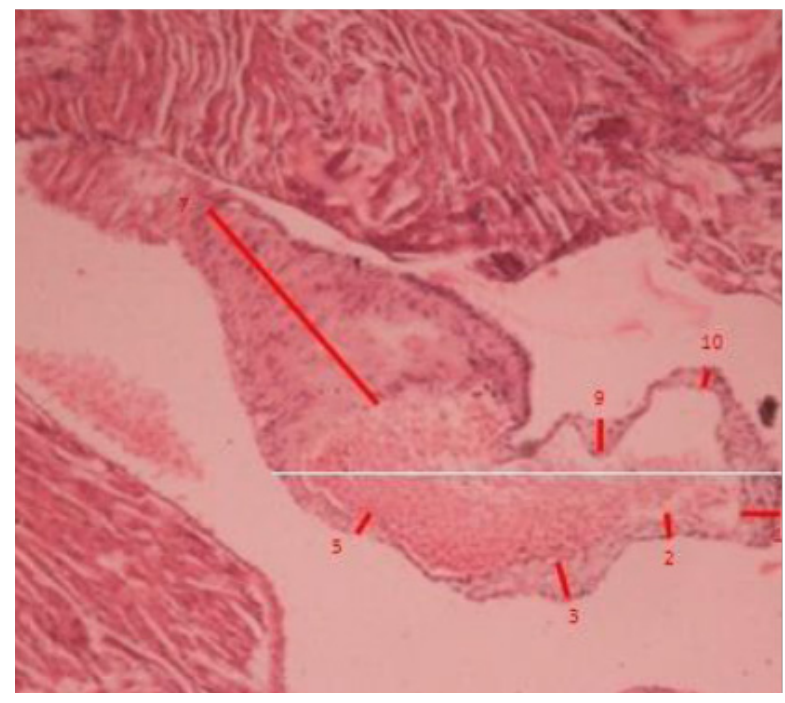

Figure 7 ApoE knock out mouse treated with the nutraceutical, observe atheroma with smaller dimensions than untreated animals. H.E.xI20.

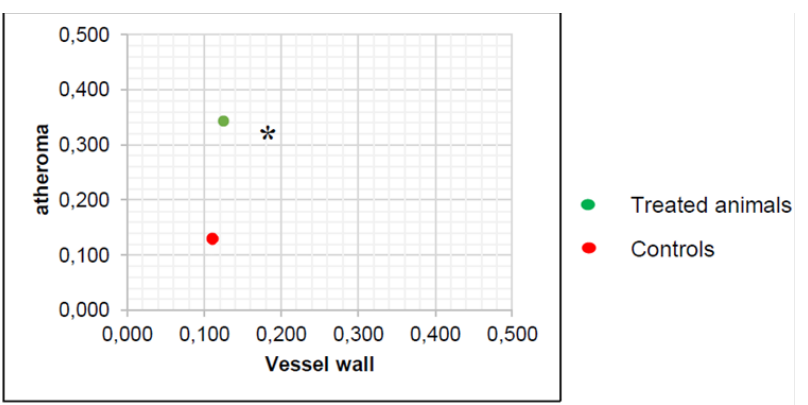

Figure 8 Ratio vessel wall/atheroma in APOE knockout mice $(n=5, * p<0.05$, Anova test). The ratio for the treated animals are significative lower that nontreated animals which confirm the anti atherogenic effect of the nutraceutical.

Table 4 Quantitative study of pathological lesions in non-treated (control) ApoE knockout mice

\section{Control (non treated animals)}

\begin{tabular}{llll}
\hline Reference & \multicolumn{2}{l}{ Relative ratio to the reference line } \\
\hline Line & Vessel wall & Atherome & Vessel wall + Atheroma \\
\hline 1 & 0.15 & & \\
2 & 0.18 & 0.46 & 0.64 \\
3 & 0.27 & 0.49 & 0.76 \\
4 & 0.16 & & \\
Mean value & 0.19 & 0.475 & 0.7 \\
\hline
\end{tabular}


Table 5 Quantitative study of pathological lesions in treated ApoE knockout mice

\begin{tabular}{llll}
\hline \multicolumn{4}{l}{ Treated animals } \\
\hline Reference & \multicolumn{2}{l}{ Relative ratio to the reference line } \\
\hline Line & Vessel wall & Atherome & Vessel wall + Atheroma \\
\hline 1 & 0.02 & 0.07 & 0.08 \\
2 & 0.01 & 0.04 & 0.05 \\
3 & 0.02 & 0.06 & 0.08 \\
5 & 0.01 & 0.03 & 0.04 \\
7 & 0.34 & 0.16 & 0.5 \\
9 & 0.01 & 0.06 & 0.07 \\
10 & 0.01 & 0.04 & 0.05 \\
Mean Value & 0.059 & 0.066 & 0.124 \\
\hline
\end{tabular}

As a conclusion, the nutraceutical from C. longa showed antiinflammatory activity in the cotton disc-induced granuloma model, reducing systemic inflammation and cell infiltration. It also showed cytotoxic potential in the human tumor line NCI-H460 with a high antiproliferative activity in this line. It would be interesting to evaluate the crude extract of $\mathrm{C}$. longa in other inflammation models in a dose range that includes the determined average effective dose and to confirm at cellular and molecular level, the possible mechanisms responsible for the observed anti-inflammatory, antioxidant and cytotoxic activity. The trials with APOE knockout mice demonstrated the nutraceutical lipid lowering effects as demonstrated by biochemical and pathological tests. The nutraceutical promoted a significant decrease in cholesterol and triglyceride levels in favor of treated animals. This corresponds to the decrease in lesion processes at the cardiovascular system level in the animals that received the treatment. Although the beneficial effects of the nutraceutical are related to their lipid lowering actions, the histo-pathological observations suggest the existence of various beneficial effects on the vascular wall, beyond the lipid reduction.

\section{Acknowledgments}

There is not external financial support provided for this research work.

\section{Conflicts of interest}

There is not conflict of interest.

\section{References}

1. Benavides A, Hernández RE, Ramírez H, et al. Tratado de Botánica Económica Moderna. Universidad Autónoma Agraria Antonio Narro: Buenavista, Saltillo, Coah, México; 2010.

2. Grynkiewicz, G. Slifirski, P. Curcumin and curcuminoids in quest for medicinal status. Acta Biochimica Polonica (ABP). 2012;59 (2):201-212.
3. Blumenthal M, Goldberg A, Brinckmann J. Eds. Herbal Medicine: Expanded Commission E Monographs. Austin, TX: American Botanical Council; Newton, MA: Integrative Medicine Communications; 2000.

4. Taylor R, Leonard M. Curcumin for Inflammatory Bowel Disease: A Review of Human Studies. Altern Med Rev. 2011;16(2):152-156.

5. Vasant L, Frawley D. "Curcuma longa", in energy and healing power of the plant world: Ayurvedic Guide to herbs and plants. Barcelona, Ediciones Apóstrofe; 1997. 205-206 p.

6. Tayyem RF, Heath DD, Al-Delaimy WK, et al. Curcumin content of turmeric and curry powders. Nutr Cancer. 2006;55(2):126-131.

7. Boaz M, Leibovitz E, Bar Dayan Y, et al. Functional foods in the treatment of type 2 diabetes: olive leaf extract, turmeric and fenugreek, a qualitative review. Func Foods Health Dis. 2011;1(11):472-481.

8. Lin JK, Chen YC, Huang YT, et al. Suppression of protein kinase C and nuclear oncogene expression as possible molecular mechanisms of cancer chemoprevention by apigenin and curcumin. $J$ Cell Biochem Suppl. 1997;29:39-48.

9. Cheng AL, Hsu CH, Lin JK, et al. Phase I clinical trial of curcumin, a chemopreventive agent, in patients with high-risk or pre-malignant lesions. Anticancer Res. 2001;21(4B):2895-2900.

10. Park J, Conteas CN. Anti-carcinogenic properties of curcumin on colorectal cancer. World J Gastrointest Oncol. 2010;2(4):169-176.

11. Boyanapalli SS, Kong AT. "Curcumin, the King of Spices": Epigenetic Regulatory Mechanisms in the Prevention of Cancer, Neurological, and Inflammatory Diseases. Curr Pharmacol Rep. 2015;1(2):129-139.

12. Jones DP. Radical-free biology of oxidative stress. Cell Physiology. 2008;295:C849-868.

13. Haigis MC, Yankner BA. The aging stress response. Mol Cell. 2010;40(2):333-344.

14. Navarro-Yepes J, Burns M, Anandhan A, et al. Oxidative Stress, Redox Signaling, and Autophagy: Cell Death Versus Survival, Antioxid Redox Signal. 2014;21(1):66-85.

15. Esme H, Cemek M, Sezer M, et al. High levels of oxidative stress in patients with advanced lung cancer. Respirology. 2008;13(1):112-116.

16. Guerra JIE. Estrés oxidativo, enfermedades y tratamientos antioxidantes. An Med Interna. 2001;18(6):326-335.

17. Wei Z, Wang SY. Antioxidant activity and phenolic compounds in selected herbs. J Agric Food Chem. 2001;49(11):5165-5170.

18. Shokolenko I, Venediktova N, Bochkareva A, et al. Oxidative stress induces degradation of mitochondrial DNA. Nucleic Acids Res; 2009;37(8):2539-2548.

19. Wiseman H, Halliwell B. Damage to DNA by reactive oxygen and nitrogen species: role in inflammatory disease and progression to cancer. Biochem J. 1996;313(Pt 1):17-29.

20. Brand-Williams W, Cuvelier ME, Berset C. Use a of free radical method to evaluate antioxidant activity. Food Sci Tecnol. 1995;28(1):25-30.

21. Benzie IF, Strain JJ. The ferric reducing ability of plasma (FRAP) as a measure of antioxidant power: the FRAP assay. Anal Biochem. 1996;239(1):70-76.

22. Ishiyama $\mathbf{M}$, Tominaga $\mathrm{H}$, Shiga $\mathbf{M}$, et al. A combined assay of cell viability and in vitro cytotoxicity with a highly water-soluble tetrazolium salt, neutral red and crystal violet. Biol Pharm Bull. 1996;19(11):1518-1520. 
23. Geethanjali A, Lalitha P, Jannathul Firdhouse M. Analysis of Curcumin Content of Turmeric Samples from Various States of India. International Journal of Pharma and Chemical Research. 2016;2(1):55-62.

24. Ravindran PN, Nirmal Babu K, Sivaraman K. Turmeric: The Genus Curcuma. Medicinal and aromatic plants-industrial profiles. CRC Press; 2007.
25. Sahebkar A. A systematic review and meta-analysis of randomized controlled trials investigating the effects of curcumin on blood lipid levels. Clin Nutr. 2014;33(3):406-414.

26. Maheshwari RK, Singh AK, Gaddipati J, et al. Multiple biological activities of curcumin: a short review. Life Sci. 2006;78(18):2081-2087. 